\section{Is rubber monoculture banishing agrobiodiversity and happiness? evidences from shifting cultivation landscape of Tripura, northeast India}

\author{
D. K. Pandey ${ }^{1, *}$, P. Adhiguru ${ }^{2}$, Uma Sah ${ }^{3}$, \\ N. Devachandra ${ }^{1}$, S. K. Dubey ${ }^{4}$ and \\ Chandra Deo ${ }^{1}$ \\ ${ }^{1}$ College of Horticulture and Forestry, Central Agricultural University, \\ Pasighat 791 102, India \\ ${ }^{2}$ Division of Agricultural Extension, Krishi Anusandhan Bhavan-I, \\ ICAR, New Delhi 110 012, India \\ ${ }^{3}$ ICAR-Indian Institute of Pulses Research, Kanpur 278 002, India \\ ${ }^{4}$ ICAR-Agricultural Technology Application Research Institute, \\ Kanpur 278 002, India
}

Natural environmental settings, in general, are considered by humans as the ideal ambience which makes them happy and reinvigorated especially within their mental realm. If this is the case, can we assume that all green spaces are synonymous to augmenting happiness? Biodiversity is expressed in terms of a system having number and abundance of different species. For resilience of various ecosystem services like food production, climate regulation, and pest management to take place, prevalence of such biodiversity is essential which can substantially contribute to sustained human well-being. In this study, we assessed the status of agrobiodiversity and subjective well-being of an indigenous community amidst the transition from shifting cultivation (SC) to monoculture of natural rubber (NR). Sampling the respondents from 18 villages of Dhalai, Tripura, a remotely located district in northeast India and bordered by Bangladesh, we used mixed methods research for in depth investigation. Findings revealed that in the SC landscape of study area, the cultivated crop species and livestock breeds were being largely replaced by encroachment from rubber plantation. We documented only 19 crop species on such a landscape which is otherwise known for its vast agrobiodiversity in the tropics. This kind of transition from SC to NR which is usually supported by the government development interventions, has severely affected the ecosystem services of such landscapes and banishing happiness from the indigenous communities, as perceived by them. Hence stabilization of rich agrobiodiversity and simultaneously ensuring the peoples' well-being is the only potential alternative for development in the region.

Keywords: Agrobiodiversity, indigenous community, northeast India, rubber plantation, shifting cultivation landscape.

SHIFTING cultivation (SC), alternately called slash-andburn agriculture (locally jhum), is an extensive farming

*For correspondence. (e-mail: dkpextension@gmail.com) system $^{1,2}$ practised across around 280 million hectares worldwide $^{3}$, including tropical and subtropical areas of Africa, America, Asia, Pacific and Caribbean. As one of the major agricultural systems, this system is potentially serving as a source of livelihood for half a billion people around the globe ${ }^{4,5}$. Indeed, SC can support millions of people in the tropics in terms of sustaining their ecosystems, livelihoods, culture and food security ${ }^{6-9}$. However, due to prolonged adherence to the ill-conceived view that $\mathrm{SC}$ is a ruinous system which can pave way for depletion of forest resources and degradation of associated ecology, governments in Southeast Asia have consistently attempted to control or terminate it through various measures such as bans, forced resettlement, declaration of forest reserves, monetary incentives, crop substitution and so on. In spite of such kinds of policies and measures by Governments, there was no significant improvement in the environmental conditions. Also, Governments through various programmes have promoted various land use changes for conversion of SC landscapes to rubber (Hevea brasiliensis) plantation. Though the economic benefits of cultivation of single-species monocultural plantation have been recognized, however, such cultivations have drawn criticisms from various researchers that such kind of plantations have demerits due to several negative impacts in terms of social and environmental aspects $^{10,11}$. One of the often criticized social impacts is that the large private companies benefiting from the shift in ownership to them, which was originally from local communities, due to transition towards large-scale plantations. Such a shift in ownership, in turn brought in other undesirable social impacts such as inequality in distribution of resources, imbalanced livelihoods arising due to forced resettlement having characteristics like vanishing traditional goods and cultures, and loosing customary rights $^{12,13}$. In an another study conducted in South Asian countries, i.e. Sri Lanka, Bangladesh and India including the state of Tripura, it was observed that, though the rubber plantations increased forest coverage in planted areas, they also led to the decline of local biodiversity ${ }^{14,15}$. Study conducted in Xishuangbanna, China revealed that fertilizer run-off from rubber plantations resulted in waterway eutrophication, reduction in filtering services by aquatic vegetation, and frequent contamination of well water $^{16}$. Also, expansion of rubber cultivation led to reduced diversity in the case of benthic macro invertebrates ${ }^{17}$. Thus, these findings indicate that in Southeast Asia, the extinction crisis may worsen with the expansion of rubber plantations. Contrary to rubber plantations, biocultural landscapes like SC, support human well-being related to recreational and exercise opportunities, and the richness of biodiversity could support many cultural, intellectual and spiritual traditions ${ }^{18,19}$. With the advent of the Millennium Ecosystem Assessment (2005), it was recognized that human well-being could be supported by ecosystem services. Though, poor farmers may be aware 
of the value of ecosystem services, sometimes they will be constrained to take action for conserving them due to more immediate economic pressures ${ }^{20}$, or because they do not own the titles to land they cultivate, as in the case of SC land.

It is observed by psychologists that people in general tend to return to a particular determined level of happiness in spite of ups and downs in their life. This kind of behaviour is conceptualized as 'the hedonic treadmill', in other words hedonic adaptation. Such behaviour is due to the fact that people adapt quickly to happiness-inducing stimuli and may repeatedly return to their happiness set points, after a temporary rise or fall in well-being regardless of what happens to them. Introduction of variety and novelty in stimuli is one of the effective options to combat such adaptation behaviour of the people. In this parlance, a richer variety of natural stimuli is present in natural environment since it is abundant with diversity. Thus, such an ambience emanating from natural environment may weaken the hedonic adaptation of people. This theoretical assumption having relevance and potential for land use planning and promoting conservation remains largely untested. In the given context, the present study examines the status of agrobiodiversity in SC system at landscape level and also presents an assessment of self-reported subjective well-being linked to a range of cultural ecosystem services, obtained from their SC landscapes amidst such transitions.

India is currently the sixth highest producer and second highest consumer of natural rubber (NR) in the world, with an area of around 822,000 ha (ref. 21). It is largely grown $(91 \%)$ by small holders, tribals and other resource poor communities. Rubber is a tropical crop and grows well in Tripura which is the second largest producer of NR in the country. Since 1976, there was emphasis on rubber production in Tripura with the establishment of Tripura Forest Development and Plantation Corporation Limited (TFDPC Ltd.), which took up the issue of improvement of degraded forestlands as a principal strategy and simultaneously to disengage a cluster of tribals from SC by providing wage employment through rubber plantation $^{22}$. Further, the thrust on rubber plantations was strengthened with the launch of the World Bank aided Block Planting Scheme or Tripura Block Plantation Project (BPS) in 1992 and implemented jointly by the Rubber Board of India and Govt of Tripura (Department of Tribal Welfare). The objective of BPS was to attract marginal and small farmers who cultivated other crops to NR cultivation and expand the area under NR. As a result, the area under NR cultivation recorded $89 \%$ growth, whereas, the area under SC declined up to $63 \%$ in Tripura $^{23}$ between 2000-2001 and 2010-2011. It was the highest rate of growth compared to any other state including traditional and non-traditional areas of NR, and in 2017-18, the area under rubber plantation in Tripura reached up to 84,480 ha (ref. 24).
The present study was conducted in 18 purposively sampled villages in Dhalai district $\left(23^{\circ} 50^{\prime} 48.1128^{\prime \prime} \mathrm{N}\right.$ and $91^{\circ} 54^{\prime} 35.73^{\prime \prime} \mathrm{E}$ ) of Tripura (Figure 1). The northern and eastern boundaries of the district are bounded by Bangladesh. The district is mostly uneven and hilly and has less plain area suitable for habitation of tribal population, than that of any other district. Thus, it is a tribal district having $56 \%$ tribal population and an overwhelming $76 \%$ of them are dependent on agriculture for their livelihood ${ }^{25}$. This remote district has a low human population density ${ }^{26}(158$ people per $\mathrm{km}^{2}$ ) and a relatively high forest $\operatorname{cover}^{27}$ of about $82.50 \%$. The major tribes are Tripuri, Reang, Kuki (Halam/Darlong/Hrangkhawl), Koloi and Chakma. Reangs are one of the Primitive Tribal Groups (PTG) as classified by the Government of India.

For the present study, the selected 18 ethnic villages of Dhalai district were chosen from two tribal development blocks namely, Ambassa and Ganganagar, keeping in view the concentration of indigenous tribes, their dependency on SC and accessibility to study area. Further, we conducted a pilot survey of 150 households (HH) in both the blocks (75 each) and isolated one third HH (50) based on some features and potentials to fulfill the objectives of the study. We used criteria such as age of the HH head, years of SC experience, extent of influence by monoculture of NR, social participation, particularly, involvement in communal decision for choice of crops being/to be cultivated on SC land, as farming is mainly a co-operative act on such land in the region. Finally, we focused on 50 $\mathrm{HH}$ heads for in depth investigation on agrobiodiversity in SC landscape (SCL) comprising the components of SC plot, fallow patch, plot under settled cultivation and homestead gardens including usage of wild edible plants and to measure subjective well-being. Free Prior

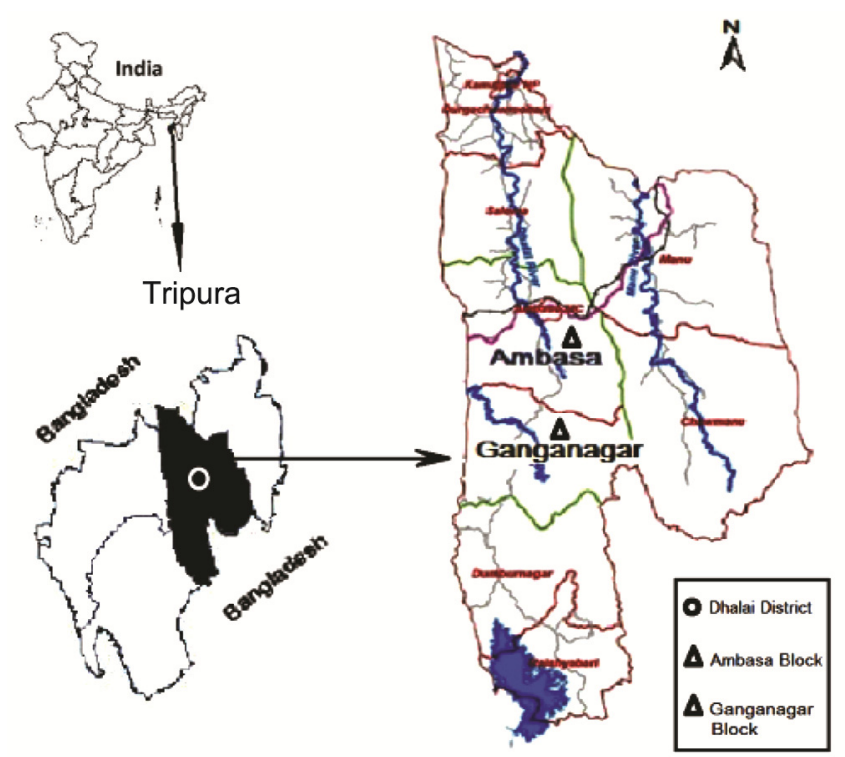

Figure 1. Map of the study area. 
Informed Consent (FPIC) agreement was discussed with the community and later was signed by their representatives. The conditions of the research process, which were mutually agreed upon, were briefed in the FPIC agreement, by explaining possible benefits to those communities who were involved in the study and also under what conditions data to be shared and used. Structured survey schedule including checklist of cultivated plants was used to examine the prevailing diversity. This was followed by focused group discussion (FGD) and transact walk with SC practitioners and key informants which was conducted to triangulate the responses of common concern, i.e. impact of NR monoculture on agrobiodiversty and socio-cultural services. Thus, multistage sampling procedure was adapted to arrive at logical findings. In the absence of benchmark data on the decline of species landraces, wild edible plants and ecosystem service degradation (intangible ${ }^{28}$ ), such aspects were measured based on respondents' perception towards extent of prevalence of biodiversity over past two decades by quantifying them in a ten-point scale in interval level and then converted to percentage. The responses were recorded in appropriate categories, i.e. $0-10 \%$ indicates the least depletion and $90-100 \%$ indicates total depletion. This was triangulated during FGD and presented as results.

Simpson (1949) developed diversity index for measuring crop diversity index. Because the instrument was simple and easy to use, its acceptability was quite high ${ }^{29}$. Crop diversity was calculated using the following formula of Simpson Diversity Index (SDI)

$$
D=1-\frac{\sum n(n-1)}{N(N-1)},
$$

where $n$ is the number of individuals of each species, $N$ the total number of individuals of all the species.

The Cantril's Self-Anchoring Scale ${ }^{30}$ was used to measure respondents' subjective well-being as there is no single 'correct' method to assess subjective well-being across all research situations and purposes ${ }^{31}$. Moreover, it is the most enduring and widely used single-item measure, that has demonstrated high reliability ${ }^{32}$. It is frequently used in large-scale survey studies, most notably in the case of international researches conducted by Gallup Organization ${ }^{33}$. The grouping pattern (suffering, struggling and thriving) formed by Gallup ${ }^{34}$ was adopted for interpretation of results. Considering the ladder of life scale developed by Cantril and his colleagues, the respondents were characterized based on how they view both their present life and their near future (five years down the line). 'Thriving' implies that the respondents have positive views of the current life and a lot of hope for the next five years. Whereas, 'suffering' respondents have a faint outlook on the present life and perceive little hope for the future and the remaining respondents appear to be 'struggling' or just getting by. As per the requirements, data were subjected to statistical analysis to draw meaningful interpretations and conclusions.

Figure 2 shows the results revealing the most frequently recorded species/breed in SCL. Field crop cultivation was reported as the principal crop grown by the upland tribes of Dhalai.

Figure 2 further shows that on SCL in the study area we could find and record only 22 types of species. Of these 22 types of species, there were 6 field crops, 7 species of vegetables, 4 species of condiments and spices, 2 species of fruit crops being cultivated, and 3 species of livestock being reared by the respondents. All the sampled respondents reported $100 \%$ of rice (Oryza sativa) cultivation in SC land (locally known tilla land) as well as in land available for settled cultivation (locally known lunga land). Sesame (Sesamum indicum), an oilseed crop and pigeon pea (Cajanus cajan), a pulse crop were found to be the most predominantly cultivated species followed by maize (Zea mays) and cotton (Gossypium spp.), which was mainly concentrated on tilla land. Among vegetable crops, we found that potato was the most preferred species by the respondents followed by ash gourd, collocasia

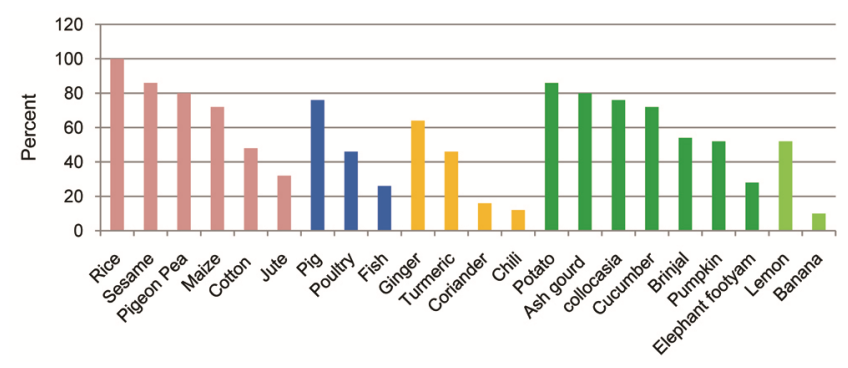

Figure 2. Percentages of the most frequently recorded species/breed in the sample area.
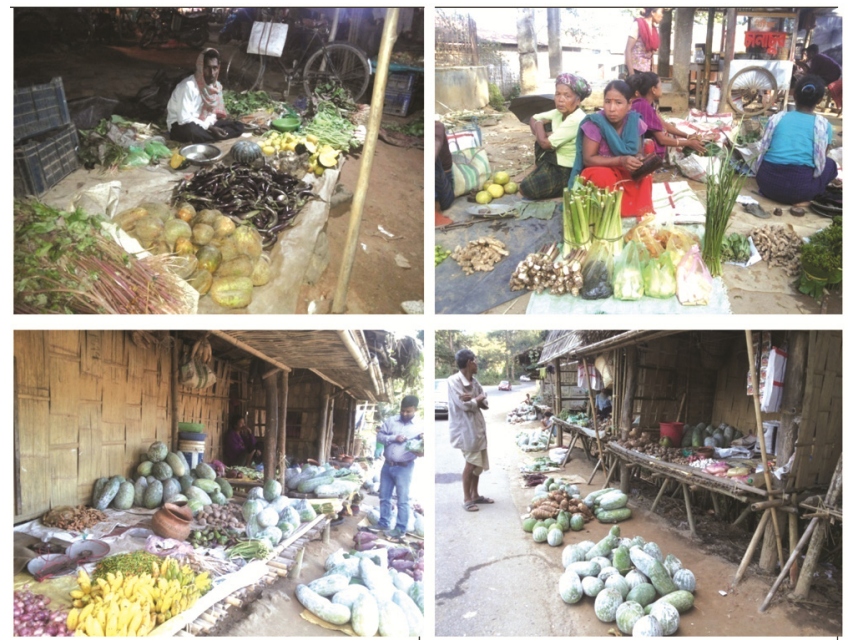

Figure 3. Local market vendors of Kulai and Ambasa, Dhalai, Tripura selling cucumber, brinjal, pumpkin, banana, ash gourd and other vegetables. 
and cucumber. In the case of fruit crops, lemon was reported as the most preferred crop followed by banana which was mainly grown on SC fallow. Only 3 types of livestock species were recorded namely pig, poultry and fish. The given visuals (Figure 3) also provide evidence for poor species richness in the study area.

We worked out the crop diversification index based on the HH level information of tribals and the data was triangulated during FGD and the results are presented in Figure 4.

Figure 4 reveals the Simpson's diversity index value for the sample area which depicted that the maximum species diversity was found in vegetable crops followed by cereal crops and livestock. Least species diversity was found in case of fruit crops and pulse crops too recorded minimum extent of diversity in the given ecology. As the study locale is rich in flora and fauna, several indigenous vegetables are being grown there with their culinary preferences among the SC practitioners. Similarly, cereals like paddy, jowar and maize had vast diversity in the region and so were their higher diversity index.

The extent of collection and usage of wild edible plants (WEP) by the respondents from SC fallow/adjacent forest in the study area is presented in Figure 5.

Figure 5 shows the usage of wild edible plants (WEP) particularly bamboo shoot (a delicacy among tribals), which was reported by $93 \%$ respondents followed by medicinal and aromatic plants $(69 \%)$. Collection and usage of edible fruits was reported by about one-fourth of the

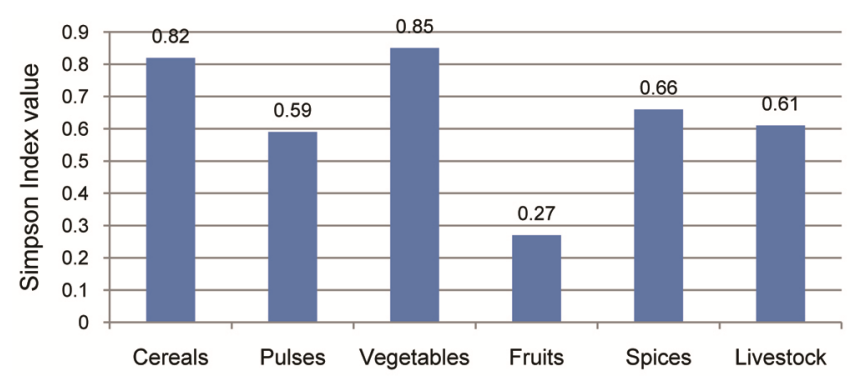

Figure 4. Simpson's diversity index value for the sample area.

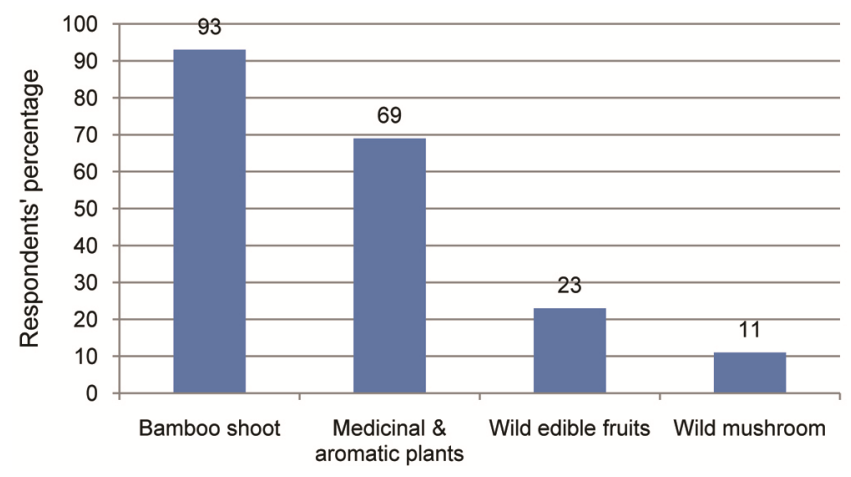

Figure 5. Usage of wild edible plants in sample area. respondents whereas availability and usage of mushroom was found among one-tenth of the total respondents.

Table 1 depicts the decline in the rate of crop species/ landraces, availability of WEP and reduction in ecosystem services in SCL as perceived by the respondents in the study area. Findings on ecosystem services, i.e. the benefits they provided, which were rendered by SCL in the past, showed that they had severely degraded and declined due to shrinking of biodiversity in the landscape. This was mainly attributed to the increasing area under NR plantation as revealed by the respondents. Similarly, significant decrease in the availability of WEP, another component of ecosystem services, was also due to such land use change. Further, half of the species and their landraces also were squeezed in the sample area over a period of time, which the respondents attributed to the changes in the food preference among new generation and market oriented production mainly cultivation of cash crops.

Assessment of the status of well-being of the respondents indicated that $92 \%$ of them perceived their wellbeing as moderate or inconsistent (Figure 6). They were either struggling in the present, or expecting more struggle in future. Such people are less likely to eat healthy food and more likely to indulge in drinking and smoking. However, only $2 \%$ reported strong, consistent, and progressive well-being. These respondents have positive views of their present life situation and they look for betterment of the quality of their life in next five years. A meagre $(6 \%)$ proportion of respondents perceived wellbeing that was at high risk. They seem to have inadequate access to basic amenities of life, i.e. food, shelter and clothing. These respondents gave poor ratings of their present life situation (below 4 on a scale of 10). They were less optimistic about the improvement of their wellbeing status in near future.

Our study evidently demonstrated the loss of exceptional agrobiodiversity after SC conversion to rubber plantation, thereby significant degradation in ecosystem services which has ultimately affected the well-being of the ethnic groups in the study area. The study documented only 19 crops species and 3 livestock species on SCL, although such landscapes are rich particularly in terms of agrobiodiversity as reported in several stu$\operatorname{dies}^{35,36}$. A recent assessment on crop species diversity in $\mathrm{SC}$ system of Eastern Himalayas has reported thirty plus crops species grown in $\mathrm{SC}^{37}$. Further, the level of usage of WEP as reported by the respondents (Figure 5) clearly indicates their decline on the SC landscape amidst NR monoculture. In fact, the expansion of rubber plantations in SC plots has, to a large extent, taken place in agrobiodiversity-rich areas and that the plantations are exclusively grown as monocultures. This has led to substantial (agro) biodiversity losses and this transition from SC to rubber plantations has also reduced diversity of landscape and agricultural systems, thus negatively affecting the 


\section{RESEARCH COMMUNICATIONS}

Table 1. Respondents' perception on decline in landraces/crops species, WEP and ecosystem services

\begin{tabular}{lcl}
\hline Category & Decline percentage (\%) & \multicolumn{1}{c}{ Reasons for decline } \\
\hline Crop species & 50 & Change in food preference among new generation \\
WEP & 60 & Market oriented production \\
Ecosystem services & 80 & Conversion of native/natural forest into NR monoculture \\
\hline
\end{tabular}

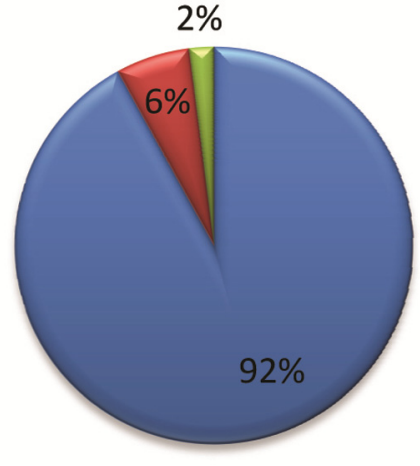

- Suffering

- Struggling

$\square$ Thriving

Figure 6. Status of subjective well-being of respondents.

availability of habitat types for species originating from natural forests.

Over $90 \%$ respondents have reported their subjective well-being (SWB) as 'struggling' or just 'getting by' (Figure 6). In other words, they are compelled to manage or continue to exist in a state or situation where something is lacking. In fact, individual SWB is increasingly linked with cultural values ${ }^{38}$, whereas $\mathrm{SC}$ is integral to indigenous culture which often involves the exercise of sophisticated indigenous technical knowledge. In many ethnic cultures, the non-material cultural practice of SC is intimately associated with the social order, with authority and decision-making powers over resource access and allocation as well as with festivals, rituals and the sense of sacred ${ }^{38}$. There are often reciprocal collective labour activities around the cultivation calendar such as collective clearing, fire management, collective harvesting and so on, whereas, NR monoculture weans away all these activities. Cultural services are deeply interconnected with each other and often connected to provisioning and regulating services. For example, small scale fishing is not only about food and income, but also about fishers' way of life ${ }^{18}$. In many situations, cultural services of an ecosystem are among the most important values people associate with Nature - it is therefore critical to understand them. From time immemorial, local and indigenous communities in India have developed traditions, representations, and beliefs about forests and biodiversity. The cultural practices and beliefs of a community play a significant role in enhancing community-based initiatives, particularly in achieving sustainability in the long term ${ }^{39}$. However, keeping aside these concerns for a while, and considering the important linkages between land use changes and livelihood differentiation, vulnerability and inequalities, have highlighted that the SC systems achieve an effective multi-functional balance at landscape level between food production and other 'ecosystem service' benefits $^{40}$. The primary purpose of cultivation is to reliably produce nutritious food, and indeed the method generally achieves this under certain conditions, providing excellent well-being for families and communities where there are equitable social structures and security tenures $^{38}$. Shift from SC to NR plantation certainly influences all these aspects and subsequently erase the happiness of the indigenous communities. The study results revealed that in the presence of natural environment settings, tribal people tended to be happier and reinvigorated and also found that all green spaces were not equal in promoting happiness and sustaining ecosystem services which depended on biodiversity and ecosystem functions.

Declaration. All the authors hereby declare that they have no conflict of interest in this publication.

1. Peng, L., Zhiming, F., Luguang, J., Chenihual, L. and Jingua, Z., A review of swidden agriculture in Southeast Asia. Remote Sens., 2014, 6, 1654-1683; https://doi.org/10.3390/rs6021654.

2. Schuck, E. C., Nganje, W. and Yantio, D., The role of land tenure and extension education in the adoption of slashes and burn agriculture. Ecol. Econ., 2002, 43, 61-70; https://doi.org/10.1016/ S0921-8009(02)00180-5.

3. Heinimann, A. et al., A global view of shifting cultivation: recent, current, and future extent. PLoS ONE, 2017, 12(9), e0184479; https://doi.org/10.1371/journal.pone.0184479.

4. van Vliet, N. et al., Trends, drivers and impacts of changes in swidden cultivation in tropical forest-agriculture frontiers: a global assessment. Global Environ. Chang., 2012, 22, 418-429; https:// doi.org/10.1016/j.gloenvcha.2011.10.009.

5. Craswell, E. T., Sajjapongse, A., Howlett, D. J. B. and Dowling, A. J., Agroforestry in the management of sloping lands in Asia and the Pacific. Agroforest. Syst., 1997, 38, 121-137; https:// doi.org/10.1023/A:1005960612386.

6. Bruun, T. B., Berry, N., de Neergaard, A., Xaphokahme, P., McNicol, I. and Ryan, C. M., Long rotation swidden systems maintain higher carbon stocks than rubber plantations. Agric. Ecosyst. Environ., 2018, 256, 239-249; https://doi.org/10.1016/j.agee. 2017.09.010.

7. Dressler, W. H. et al., The impact of swidden decline on livelihoods and ecosystem services in Southeast Asia: a review of the evidence from 1990 to 2015. Ambio, 2017, 46, 291-310; https:// doi.org/10.1007/s13280-016-0836-z.

8. Parrotta, J. A., Wildburger, C. and Mansourian, S., Understanding relationships between biodiversity, carbon, forest and people: the key to achieving REDD+ objectives, a global assessment report by the Global Expert Panel on Biodiversity, Forest Management, and 


\section{RESEARCH COMMUNICATIONS}

REDD+ IUFRO World Series, International Union of Forest Research Organizations (IUFRO), Vienna, Austria, 2012, vol. 31, p. 161.

9. Dalle, S. P., Pulido, M. T. and de Blois, S., Balancing shifting cultivation and forest conservation: lessons from a 'sustainable landscape' in south eastern Mexico. Ecol. Appl., 2011, 21, 1557-1572; https://doi.org/10.1890/10-0700.1.

10. Erskine, P. D., Lamb, D. and Bristow, M., Tree species diversity and ecosystem function: can tropical multi-species plantations generate greater productivity? Forest Ecol. Manage., 2006, 233 (2-3), 205-210; https://doi.org/10.1016/j.foreco.2006.05.013.

11. Alem, S., Pavlis, J., Urban, J. and Kucera, J., Pure and mixed plantations of Eucalyptus camaldulensis and Cupressus lusitanica: their growth interactions and effect on diversity and density of undergrowth woody plants in relation to light. Open J. For., 2015, 5(4), 375-386; https://doi.org/10.4236/ojf.2015.54032.

12. Baltodano, J., Monoculture forestry: a critique from an ecological perspective. In Tree Trouble: A Compilation of Testimonies on the Negative Impact of Large-scale Monoculture Tree Plantations Prepared for the 6th Conference of the Parties of the Framework Convention on Climate Change. Friends of the Earth International, Amsterdam, The Netherlands, 2000, pp. 2-10.

13. Colchester, M., Plantations for People? Arborvitae (IUCN/WWF Forest Conservation Newsletter), 2006, vol. 31, p. 7.

14. Chattopadhyay, S., Environmental consequences of rubber plantations in Kerala. National Research Programme on Plantation Development. Discussion Paper, 2015, No. 44.

15. Nath, T. K., Inoue, M. and De Zoysa, M., Rubber planting for forest rehabilitation and enhancement of commercial livelihood: a comparative study in three South Asian countries. In 18th Commonwealth Forestry Conference, Edinburgh, 2010.

16. Xu, J., Grumbine, R. E. and Beckschäfer, P., Landscape transformation through the use of ecological and socioeconomic indicators in Xishuangbanna, Southwest China, Mekong Region. Ecol. Indic., 2014, 36, 749-756.

17. Zhao, N., Wang, Z. Y., Xu, M. Z., Han, L. J. and Zhou, X. D., Research on aquatic ecology in the Naban River and restoration suggestions. In Proceedings of the International Conference on Fluvial Hydraulics (River Flow 2014) (eds Schleiss, A. J. et al.), Lausanne, CRC Press, Switzerland, 3-5 September 2014, pp. 2363-2369.

18. FAO, Sustainable Agriculture for Biodiversity. Biodiversity for Sustainable Agriculture, 2018; http://www.fao.org/3/I6602E/ i6602e.pdf.

19. Millennium Assessment, Millennium Ecosystem Assessment (Synthesis Report). Island Press, Washington DC, 2005; www. millenniumassessment.org

20. Scherr, S. J., Poverty-Environment Interactions in Agriculture: Key Factors and Policy Implications. Paper prepared for the United Nations Development Programme (UNDP) and the European Commission (EC) expert workshop on Poverty and the Environment, Brussels, Belgium, 20-21 January 1999.

21. GoI, National Rubber Policy 2019, Department of Commerce Ministry of Commerce and Industry, Government of India; https://commerce.gov.in/writereaddata/uploadedfile/MOC_636871 123490373426_National\%20Rubber\%20Policy\%202019.pdf

22. Sinha, A. K., Rubber plantations in Northeast India: hopes vs. concerns. The Tripura Foundation, 2012, p. 3.

23. MoSPI, Statistical Year Book India: 2014. Ministry of Statistics and Programme Implementation, Govt of India, 2014; http://www. mospi.gov.in/statistical-year-book-india/2014.

24. GoT, Economic Review of Tripura: 2017-18, Directorate of Economics and Statistics Planning (Statistics) Department, Government of Tripura, Agartala, 2018.

25. GoT, Dhalai District Profile: 2016, Office of the District Magistrate \& Collector, Dhalai, District, Ambassa, Tripura, 2016.
26. Chandramouli, C. and General, R., Census of India: 2011. Provisional Population Totals. New Delhi, Government of India, 2011.

27. FSI, State of Forest Report. Forest Survey of India, Dehradun, 2017.

28. Lau, J. D., Hicks, C. C., Gurney, G. G. and Cinner, J. E., What matters to whom and why? Understanding the importance of coastal ecosystem services in developing coastal communities. Ecosyst. Serv., 2019, 35, 219-230.

29. Yeom, D. J. and Kim, J. H., Comparative evaluation of species diversity indices in the natural deciduous forest of Mt. Jeombong. Forest Sci. Technol., 2011, 7(2), 68-74; doi:10.1080/21580103. 2011.573940.

30. Cantril, H., The Pattern of Human Concerns, Rutgers University Press, New Brunswick, USA, 1965.

31. Pavot, W., The cornerstone of research on subjective well-being: Valid assessment methodology. Handbook of Well-Being (eds Diener, E., Oishi, S. and Tay, L.), UT, DEF Publishers, Salt Lake City, 2018.

32. Cheung, F. and Lucas, R. E., Assessing the validity of single-item life satisfaction measures: results from three large samples. Qual. Life Res., 2014, 23(10), 2809-2818.

33. Helliwell, J. F., Layard, R. and Sachs, J., World happiness Report 2013. UN Sustainable Development Solutions Network, New York, USA, 2014

34. Gallup, G., World poll methodology. Technical Report. Washington, DC, USA, 2009.

35. Teegalapalli, K. and Datta, A., Shifting to settled cultivation: changing practices among the Adis in Central 318 Arunachal Pradesh, North-East India. Ambio, 2016, 45, 602-612; https://doi.org/ 10.1007/s13280-016-0765-x.

36. Alam, M. K. and Mohiuddin, M., Shifting cultivation (Jhum) agrobiodiversity at stake: Bangladesh Situation. Acta Hortic., 2009, 806, 709-716. https://doi.org/10.17660/ActaHortic.2009. $\underline{806.88 .}$.

37. Pandey, D. K., Adhiguru, P., Vimla Devi, S., Dobhal, S., Dubey, S. K. and Mehra, T. S., A quantitative assessment of crop species diversity in shifting 3 cultivation system of Eastern Himalayas. Curr. Sci., 2019, 117(8), 1357-1363.

38. Springate-Baginski, O., Decriminalise agro-forestry! A primer on shifting cultivation in Myanmar. Transnational Institute, Amsterdam, Netherlands, 2018.

39. Steel, P., Taras, V., Uggerslev, K. and Bosco, F., The happy culture: a theoretical, meta-analytic, and empirical review of the relationship between culture and wealth and subjective well-being. Pers. Soc. Psychol. Rev., 2018, 22(2), 128-169; https://doi.org/ 10.1177/1088868317721372.

40. Torri, M. C. and Herrmann, T. M., Spiritual beliefs and ecological traditions in indigenous communities in India: enhancing community-based biodiversity conservation. Nat. Cult., 2011, 6(2), 168191.

ACKNOWLEDGEMENT. The study is part of the ICAR Extramural research project funded by the Agricultural Extension Division, Indian Council of Agricultural Research (ICAR), New Delhi, India.

Received 24 July 2019; revised accepted 5 August 2019

doi: $10.18520 / \mathrm{cs} / \mathrm{v} 118 / \mathrm{i} 1 / 108-113$ 